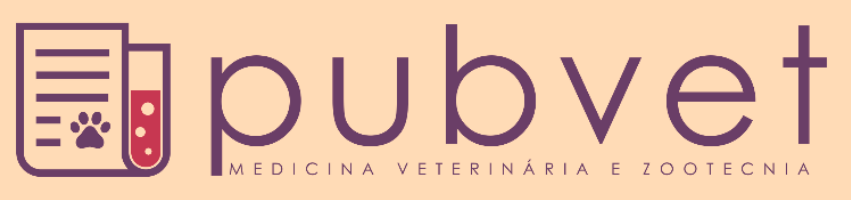

https://doi.org/10.31533/pubvet.v14n6a594.1-9

\title{
Estudo retrospectivo da tuberculose bovina no estado do Maranhão: 2013 a 2018
}

\author{
José Alfredo da Silva Oliveira ${ }^{10}$, Nancyleni Pinto Chaves Bezerra ${ }^{2}{ }^{\circ}$ (D), Adriana Prazeres \\ Paixão $^{30}$, Luciano Santos da Fonseca ${ }^{2} \bullet$ (D) \\ ${ }^{I}$ Acadêmico do curso de mestrado profissional em defesa sanitária animal. Universidade Estadual do Maranhão, Programa de pós-graduação \\ profissional em defesa sanitária animal Centro de Ciências Agrárias. São Luís, Maranhão, Brasil. \\ ${ }^{2}$ Professor adjunto I do curso de Medicina Veterinária da Universidade Estadual da Região Tocantina do Maranhão/UEMASUL/Campus \\ Imperatriz/MA; Professor Permanente do Programa de Pós-graduação Profissional em Defesa Sanitária Animal - \\ PPGPDSA/UEMA/CAMPUS São Luís/MA \\ ${ }^{3}$ Médica Veterinária/Fiscal Estadual Agropecuário da Agência Estadual de Defesa Agropecuária do Maranhão-AGED/Doutoranda do \\ Programa de Pós-Graduação Profissional em Defesa Sanitária Animal-PPDDSA-UEMA. \\ *Autor para correspondência, E-mail: alfredo3621@hotmail.com.br
}

Resumo. A tuberculose bovina é uma doença de caráter mundial. Sendo uma das principais zoonoses identificadas em abatedouros frigoríficos. As perdas econômicas estão relacionadas à baixa produtividade, queda na conversão alimentar, reprodução e à condenação de carcaças em matadouros, por isso, os métodos de controle desta enfermidade no Brasil são definidos pelas normativas do Programa Nacional de Controle e Erradicação da Brucelose e da Tuberculose Animal (PNCEBT), instituído em 2001 pelo Ministério da Agricultura, Pecuária e Abastecimento. Esse programa envolve a detecção e abate de animais reagentes, com base no teste intradérmico, que se baseia na reação de hipersensibilidade provocada pela inoculação do antígeno micobacteriano. O objetivo deste trabalho foi realizar um estudo retrospectivo do percentual de condenações de carcaças de bovinos em abatedouros frigoríficos do estado do Maranhão com base em acesso ao Sistema de Informações Gerenciais dos Serviços de Inspeção Federal e levantamento de dados de casos de tuberculose bovina em relatórios mensais de coleta de médicos veterinários autônomos habilitados no PNCEBT. Os dados encontrados por este estudo demonstra a importância da doença em âmbito estadual, Sendo que as condenações de carcaça em abatedouros frigoríficos no período de Janeiro de 2013 a Dezembro de 2018 foi de 75 condenações com destinação a graxaria, representado uma prevalência de $0,003 \%$ e os dados de casos de tuberculose bovina em mapas mensais de médicos veterinários autônomos habilitados no PNCEBT referente ao período de 2013 a 2018 foi de 20 animais positivos no total 207.557 animais examinados com prevalência de 0,009\% Embora os dados de prevalência serem baixos, podemos afirmar que a doença é endêmica no Maranhão em virtude da ausência de um inquérito sorológico estadual sobre a doença. Conclui-se que a tuberculose bovina possui grande importância zoosanitária no estado do Maranhão.

Palavras chave: bovino, estudo retrospectivo, registros de casos, tuberculose

\section{Retrospective study of bovine tuberculosis in the state of Maranhão: 2013 to 2018}
Abstract. The bovine tuberculosis is a worldwide disease, being one of the mains zoonosis identified in frigorific slaughterhouses. The economic lost are related to low productivity, fall in the food conversion, reproduction and the conviction of carcasses in slaughterhouses, therefore, the control meods of this disease in Brazil are defined by the normative from the Progama Nacional de Controle e Erradicação de Brucelose e da Tuberculose Animal (PNCBET), instituted in 2001 by the Ministério de Agricultura, Pecuária e Abastecimento. This 
progam evolves the detection and slaughter of reagentes animals, with base in the intradermal test, based in the hypersensibility reaction provoked by the inoculation of the microbacterial antigen. The objective of this work was realized a retrospective study of state of Maranhão based in the acess to the Sistema de Informações Gerenciais dos Serviços de Inspeção Federal and th survey of data from cases of bovine tuberculosis in monthly relatories of collect by autonomous veterinaries habilitaded in the PNCEBT. The data foun by this study shows the importancy of the disease in a state scope, being that the conviction of carcasses in frigorific slaughterhouses in the time period of January, 2013 to December, 2018, was a total of 75 conviction with destination to grease, representing a prevalence of $0,003 \%$ and the data of cases of bovine tuberculosis in monthly maps from autonomous veterinaries abilities in PNCEBT relative to the time period from 2013-2018 was from 20 positive animals in a total of 207.557 examined animals with prevalence of $0,009 \%$. Though the prevalence data being low, we can claim that the disease is endemic in Maranhão by virtue of absence of a state serological inquiry about the disease. Concludes that the bovine tuberculosis has great sanitary importance in the state of Maranhão.

Keywords: bovine, retrospective study, registers cases, tuberculosis

\section{Introdução}

A tuberculose é uma das principais zoonoses identificadas nos frigoríficos no Brasil. As primeiras lesões tuberculosas normalmente ocorrem no sistema respiratório, podendo ocorrer na cabeça, ou no sistema digestivo, em virtude de a bactéria seguir suas vias de entrada (Pinto, 2008). A enfermidade também ocorre em aves e mamíferos, incluindo o homem (Sabedot et al., 2009).

A diminuição da infecção pelo $M$. bovis em bovinos e a pasteurização de produtos lácteos devem ser os pilares da prevenção da doença em humanos, sendo a pasteurização do leite mais efetiva do que a inspeção em abatedouros e o teste tuberculínico em animais (Roug et al., 2014).

Em 1952, foi criado o Regulamento de Inspeção Industrial de Produtos de Origem Animal, com normativas sobre procedimentos, competências, diagnóstico clínico, macroscópico e decisões sanitárias em reposta aos agravos. A sua atualização ocorreu somente 65 anos depois com mudanças como inclusão da Análise dos Perigos e Pontos Críticos de Controle (APPCC), para garantir a inocuidade e qualidade dos produtos, inclusão de programas de auto controle no seu regulamento, a exigência de inspeção permanente em abatedouros frigoríficos, uma importante alteração foi a abertura para se inserir normas complementares por parte das unidades da federação junto aos problemas que aparecem de forma regionalizada, esclarecendo procedimentos que, até aquele momento, permaneciam sem estudo aprofundado ou omissos (BRASIL, 2017).

O Brasil possui grande potencial na produção de carne bovina, detendo um rebanho com cerca de 221,81 milhões de animais. Sendo que é o segundo lugar no ranking dos maiores rebanhos mundiais e é fornecedor de 14,40\% da produção mundial de carne (ANUALPEC, 2019). O estado do Maranhão em 2018 possuía cerca de 7.916 .550 cabeças sendo o $12^{\circ}$ maior rebanho brasileiro (ANUALPEC, 2019). O Estado do Maranhão tem uma área de $331.937 .450 \mathrm{Km}^{2}$, uma população de 6.574 .789 habitantes de acordo com o Censo do IBGE em 2010, distribuídos em 217 municípios, fazendo divisa com os estados do Pará, Tocantins e Piauí, todos com status sanitário internacional de zona livre de febre aftosa com vacinação - reconhecimento pela Organização Mundial de Saúde Animal (OIE) (AGED, 2018).

No Maranhão, existem 14 abatedouros com inspeção oficial, sendo três estabelecimentos registrados no Serviço de Inspeção Federal - SIF, cinco no Serviço de Inspeção Estadual - SIE e seis no Serviço de Inspeção Municipal - SIM. Vários fatores são elencados como responsáveis pela dificuldade de registro desse tipo de estabelecimento, como burocracia para registro, custo alto para construir, a ausência de conhecimento da população para a segurança alimentar, mercado clandestino de carne e a pequena fiscalização por parte de órgãos como a AGED ou a ANVISA, etc são mencionados como os maiores empecilhos para o aumento de novas indústrias (MARANHÃO, 2019).

Considerando que o Mycobacterium bovis acomete várias espécies animais e o homem o presente estudo teve como objetivo realizar um estudo retrospectivo da Tuberculose bovina no estado do Maranhão no período de 2013 a 2018. 


\section{Material e métodos}

O estudo foi realizado com base em análise no banco de dados dos órgãos oficiais de defesa animal do estado do Maranhão. Os dados são referentes ao período de 2013 a 2018, com dados de condenações de carcaças em abatedouros frigoríficos com SIF e mapas mensais de exames de bovinos realizados por médicos veterinários autônomos habilitados no PNCEBT. Os dados de condenações de carcaças foram obtidos no site do MAPA, por meio de acesso de informações geradas pelo Sistema de Informações Gerenciais dos Serviços de Inspeção Federal (SIGSIF), por meio de mapas e relatórios mensais on line das condenações de carcaças bovinas nos estabelecimentos, para o estudo foram consideradas as condenações por tuberculose bovina. São oriundos de três abatedouros frigoríficos com SIF (Igarapé do Meio, Imperatriz, Timon), os mesmos recebem bovinos para abate de vários estados diferentes e de mais de 100 municípios do Maranhão, para efeito do estudo foram contabilizados somente os bovinos com origem no Maranhão.

Em relação aos mapas mensais de exames de tuberculose bovina foram coletados por meio de requerimento através de documento oficial ao órgão responsável pelo Programa Nacional de Controle e Erradicação de Brucelose e Tuberculose (PNCEBT).

\section{Resultados}

No período de 01 de janeiro de 2013 a 31 de dezembro de 2018 foram abatidos 2.227 .492 bovinos de 110 municípios do estado, os dados foram coletados de três estabelecimentos sob Serviço de Inspeção Federal no Estado do Maranhão, localizados em Igarapé do Meio, Imperatriz e Timon, com registro de 75 condenações de carcaças. Os dados de condenações foram discriminados por municípios de origem dos bovinos totalizando 31 municípios com o montante de 1.684.441 bovinos. Sendo que para o estudo foram contabilizados concomitantemente as condenações de meias carcaças, cabeças e órgãos com um total de condenações de 1036 peças condenadas com destino final a graxaria (Tabela 1).

Tabela 1. Condenações de cabeças, carcaças, meias carcaças e órgãos bovinos por tuberculose bovina, destinação final das condenações e quantidade de condenações em abatedouros frigoríficos com Serviço de Inspeção Federal no período de 2013 a 2018 no estado do Maranhão.

\begin{tabular}{lcc}
\hline Parte condenada & Quantidade condenadas & Destino final \\
\hline Cabeça & 76 & Graxaria \\
Carcaça & 75 & Graxaria \\
Quarto Dianteiro & 4 & Graxaria \\
Quarto Traseiro & 2 & Graxaria \\
Baço & 68 & Graxaria \\
Cauda (Rabo) & 62 & Graxaria \\
Coração & 73 & Graxaria \\
Esôfago & 41 & Graxaria \\
Estômago & 74 & Graxaria \\
Fígado & 79 & Graxaria \\
Intestino & 74 & Graxaria \\
Língua & 74 & Graxaria \\
Pés (Mocotó) & 59 & Graxaria \\
Pulmão & 125 & Graxaria \\
Rins & 143 & Graxaria \\
\hline Total & 1036 & - \\
\hline
\end{tabular}

Fonte: Sistema de Informações Gerenciais dos Serviços de Inspeção Federal/ Ministério de Agricultura, Pecuária e Abastecimento, 2018.

Quando descriminamos os casos registrados de condenações por tuberculose bovina, podemos verificar que a sua distribuição geográfica é ampla com várias regiões do estado, isto sendo resultado a localização dos abatedouros frigoríficos que se localizam em regiões de grande fluxo de bovinos, Imperatriz, Igarapé do Meio e Timon (Tabela 2). 
Tabela 2. Condenações de carcaças bovinas por tuberculose bovina descriminadas por município de procedência dos bovinos e período em abatedouros frigoríficos com Serviço de Inspeção Federal no período de 2013 a 2018 no estado do Maranhão.

\begin{tabular}{|c|c|c|c|c|c|c|c|}
\hline \multirow{2}{*}{ Município } & \multicolumn{6}{|c|}{ Quantidade de carcaças condenações } & \multirow{2}{*}{ Total } \\
\hline & 2013 & 2014 & 2015 & 2016 & 2017 & 2018 & \\
\hline Açailândia & 2 & - & 5 & - & 3 & 5 & 15 \\
\hline Amarante do Maranhão & - & - & - & 1 & 1 & 1 & 3 \\
\hline Bacabal & - & 1 & 2 & 1 & - & - & 4 \\
\hline Bernardo do Mearim & 1 & - & - & 2 & - & - & 3 \\
\hline Bom Jardim & - & - & 1 & - & - & - & 1 \\
\hline Bom Jesus Das Selvas & - & - & - & - & - & 1 & 1 \\
\hline Buritirana & - & - & - & - & 1 & - & 1 \\
\hline Campestre do Maranhão & - & - & - & - & 1 & - & 1 \\
\hline Caxias & - & 1 & - & - & - & - & 1 \\
\hline Codó & - & - & - & - & - & 2 & 2 \\
\hline Conceição do Lago-Açu & - & - & - & 1 & - & - & 1 \\
\hline Igarapé Grande & - & 1 & - & - & - & - & 1 \\
\hline Imperatriz & - & - & 1 & - & - & - & 1 \\
\hline João Lisboa & 1 & - & 1 & - & - & 1 & 3 \\
\hline Lago da Pedra & - & - & - & - & 1 & - & 1 \\
\hline Lago dos Rodrigues & - & - & - & 1 & - & - & 1 \\
\hline Lago Verde & - & - & - & 1 & - & 1 & 2 \\
\hline Lagoa Grande do Maranhão & - & - & - & 1 & - & - & 1 \\
\hline Lajeado Novo & - & - & - & - & - & 1 & 1 \\
\hline Maracaçumé & - & - & - & - & - & 4 & 4 \\
\hline Olho D'Água Das Cunhãs & - & 1 & - & 1 & - & - & 2 \\
\hline Pastos Bons & - & 1 & - & - & - & - & 1 \\
\hline Ribamar Fiquene & - & - & 3 & 1 & 1 & - & 5 \\
\hline Santa Inês & - & - & - & 2 & 1 & 1 & 4 \\
\hline Santa Luzia & - & - & 3 & - & - & 2 & 5 \\
\hline São Domingos do Maranhão & - & - & 1 & - & - & & 1 \\
\hline Senador La Rocque & - & 2 & - & - & - & 1 & 3 \\
\hline Sitio Novo & - & - & - & - & 1 & - & 1 \\
\hline Vila Nova dos Martírios & - & 1 & - & - & - & 1 & 2 \\
\hline Vitorino Freire/MA & - & - & - & - & - & 1 & 1 \\
\hline Zé Doca/MA & 1 & & & & & & 1 \\
\hline
\end{tabular}

Do total de 110 municípios do Maranhão que enviaram bovinos para os abatedouros pesquisados, 31 municípios apresentaram bovinos com lesões sugestivas de tuberculose bovina (Tabela 3).

Tabela 3. Distribuição percentual de condenações por tuberculose bovina com o município de procedência, quantidade de bovinos abatidos, quantidade de carcaças condenadas e percentual de condenação de bovinos abatidos em abatedouros frigoríficos com serviço de inspeção federal no estado do Maranhão de 2013 a 2018.

\begin{tabular}{lccc}
\hline Município & Bovinos abatidos & No de carcaças condenadas & $\%$ de condenação \\
\hline Açailândia & 460.267 & 15 & 0,003 \\
Amarante & 76.041 & 3 & 0,004 \\
Bacabal & 92.673 & 4 & 0,004 \\
Bernardo do Mearim & 12.729 & 3 & 0,024 \\
Bom Jardim & 77.676 & 1 & 0,001 \\
Bom Jesus das Selvas & 53.038 & 1 & 0,002 \\
Buritirana & 14.196 & 1 & 0,007 \\
\hline
\end{tabular}

Próx. Pág. Continua... 
Tabela 3. Continuação

\begin{tabular}{|c|c|c|c|}
\hline Município & Bovinos abatidos & Carcaças condenadas & $\%$ de condenação \\
\hline Campestre do Maranhão & 98.960 & 1 & 0,001 \\
\hline Caxias & 16.749 & 1 & 0,006 \\
\hline Codó & 53.283 & 2 & 0,004 \\
\hline Conceição do Lago Açú & 5.879 & 1 & 0,017 \\
\hline Igarapé do Meio & 5.911 & 1 & 0,017 \\
\hline Imperatriz & 67.171 & 1 & 0,001 \\
\hline João Lisboa & 49.562 & 3 & 0,006 \\
\hline Lago da Pedra & 34.749 & 1 & 0,003 \\
\hline Lago dos Rodrigues & 4.203 & 1 & 0,024 \\
\hline Lago Verde & 39.288 & 2 & 0,005 \\
\hline Lagoa Grande do Maranhão & 16.385 & 1 & 0,006 \\
\hline Lajeado Novo & 7.307 & 1 & 0,014 \\
\hline Maracaçumé & 2.871 & 4 & 0,139 \\
\hline Olho D’água das Cunhãs & 69.423 & 2 & 0,003 \\
\hline Pastos Bons & 307 & 1 & 0,326 \\
\hline Ribamar Fiquene & 11.749 & 5 & 0,043 \\
\hline Santa Inês & 44.268 & 4 & 0,009 \\
\hline Santa Luzia & 115.446 & 5 & 0,004 \\
\hline São Domingos do Maranhão & 2.077 & 1 & 0,048 \\
\hline Senador La Rocque & 107.399 & 3 & 0,003 \\
\hline Sitio Novo & 6.740 & 1 & 0,015 \\
\hline Vila Nova dos Martírios & 36.441 & 2 & 0,005 \\
\hline Vitorino Freire & 49.398 & 1 & 0,002 \\
\hline Zé Doca & 52.225 & 1 & 0,002 \\
\hline Total & 1.684 .441 & 75 & \\
\hline
\end{tabular}

Fonte: Sistema de Informações Gerenciais dos Serviços de Inspeção Federal/ Ministério de Agricultura, Pecuária e Abastecimento, 2018.

Embora nos abatedouros pesquisados tenham sido abatidos bovinos de ambos os sexos, o número de machos foi superior ao de fêmeas (Tabela 4).

Tabela 4. Distribuição por município de origem e distribuição por sexo de bovinos abatidos em abatedouros com serviço de inspeção federal no estado do Maranhão de 2013 a 2018.

\begin{tabular}{lccccc}
\hline Município & Machos & $\%$ & Fêmeas & $\%$ & Total \\
\hline Açailândia & 37.129 & 8,07 & 423.138 & 91,93 & 460.267 \\
Amarante do Maranhão & 2.451 & 3,22 & 73.590 & 96,78 & 76.041 \\
Bacabal & 3.391 & 3,66 & 89.282 & 96,34 & 92.673 \\
Bernardo do Mearim & 174 & 1,37 & 12.555 & 98,63 & 12.729 \\
Bom Jardim & 3.209 & 4,13 & 74.467 & 95,87 & 77.676 \\
Bom Jesus das Selvas & 8.364 & 15,77 & 44.674 & 84,23 & 53.038 \\
Buritirana & 856 & 6,03 & 13.340 & 93,97 & 14.196 \\
Campestre do Maranhão & 451 & 0,46 & 98.509 & 99,54 & 98.960 \\
Caxias & 3.998 & 23,87 & 12.751 & 76,13 & 16.749 \\
Codó & 1.262 & 2,37 & 52.021 & 97,63 & 53.283 \\
Conceição do Lago-Açu & 21 & 0,36 & 5.858 & 99,64 & 5.879 \\
Igarapé do Meio & 523 & 8,85 & 5.388 & 91,15 & 5.911 \\
Imperatriz & 5.021 & 7,47 & 62.150 & 92,53 & 67.171 \\
João Lisboa & 3.208 & 6,47 & 46.354 & 93,53 & 49.562 \\
Lago da Pedra & 1.826 & 5,25 & 32.923 & 94,75 & 34.749 \\
Lago dos Rodrigues & 0 & 0,00 & 4.203 & 100,00 & 4.203 \\
Lago Verde/MA & 344 & 0,88 & 38.944 & 99,12 & 39.288 \\
Lagoa Grande do Maranhão & 247 & 1,51 & 16.138 & 98,49 & 16.385 \\
Lajeado Novo & 238 & 3,26 & 7.069 & 96,74 & 7.307 \\
\hline Próx. Pág. Continu
\end{tabular}

Próx. Pág. Continua... 
Tabela 4. Continuação

\begin{tabular}{lccccc}
\hline Município & Machos & $\%$ & Fêmeas & $\%$ & Total \\
\hline Maracaçumé & 144 & 5,02 & 2.727 & 94,98 & 2.871 \\
Olho D'Águadas Cunhãs & 436 & 0,63 & 68.987 & 99,37 & 69.423 \\
Pastos Bons/MA & 0 & 0,00 & 307 & 100,00 & 307 \\
Ribamar Fiquene & 1.554 & 13,23 & 10.195 & 86,77 & 11.749 \\
Santa Inês & 1.650 & 3,73 & 42.618 & 96,27 & 44.268 \\
Santa Luzia & 4.547 & 3,94 & 110.899 & 96,06 & 115.446 \\
São Domingos do Maranhão & 81 & 3,90 & 1.996 & 96,10 & 2.077 \\
Senador La Rocque & 4.711 & 4,39 & 102.688 & 95,61 & 107.399 \\
Sítio Novo & 699 & 10,37 & 6.041 & 89,63 & 6.740 \\
Vila Nova dos Martírios & 1.546 & 4,24 & 34.895 & 95,76 & 36.441 \\
Vitorino Freire & 1.922 & 3,89 & 47.476 & 96,11 & 49.398 \\
Zé Doca & 992 & 1,90 & 51.233 & 98,10 & 52.225 \\
\hline Total & 90.995 & & 1.593 .416 & & 1.684 .411 \\
\hline
\end{tabular}

Fonte: Sistema de Informações Gerenciais dos Serviços de Inspeção Federal/ Ministério de Agricultura, Pecuária e Abastecimento, 2018.

Os dados sobre o levantamento de mapas mensais de exames realizados por médicos veterinários autônomos habilitados no Programa Nacional de Controle e Erradicação de Brucelose e Tuberculose, com total de animais examinados de 207.557 animais examinados com ocorrência de 20 casos positivos de tuberculose bovina no período de 2013 a 2018 (Tabela 5).

Tabela 5. Registros de relatórios mensais de exame de tuberculose bovina por médicos veterinários autônomos habilitados no Programa Nacional de Controle e Erradicação de Brucelose e Tuberculose, com população total de bovídeos do estado, população de bovinos examinados, quantidade de exames positivos e percentual de positivos em relação a examinados no 2013 a 2018 no estado do Maranhão.

\begin{tabular}{lcccc}
\hline Ano & População Bovinos & Bovinos Examinados & Exames Positivos & $\%$ Positivos \\
\hline 2013 & 7.508 .400 & 39.142 & 0 & 0,00 \\
2014 & 7.488 .943 & 48.101 & 0 & 0,00 \\
2015 & 7.352 .093 & 37.508 & 1 & 0,27 \\
2016 & $7,660.296$ & 25.168 & 1 & 0,40 \\
2017 & 7.675 .802 & 28.631 & 2 & 0,70 \\
2018 & 8.005 .623 & 29.007 & 16 & 4,83 \\
\hline
\end{tabular}

Fonte: Programa Nacional de Combate e Erradicação de Brucelose e Tuberculose/ Agência Estadual de Defesa Agropecuária do Estado do Maranhão

\section{Discussão}

Os resultados sobre condenações de bovinos por lesões sugestivas de tuberculose bovina abatidos em abatedouros frigoríficos com Serviço de Inspeção Federal no estado do Maranhão de 2013 a 2018 com 75 condenações de um montante de 2.227 .492 bovinos com prevalência de 0,003 estão abaixo do obtido por Pereira (2011) que realizou pesquisa no período de 2002 a 2009 que pesquisou condenações de tuberculose bovina nos mesmos abatedouros frigoríficos com condenação de 295 carcaças bovinas de um total de 1.659 .952 bovinos com prevalência de $0,02 \%$.

Os dados de prevalência baixos de condenações de carcaças encontrados por este estudo, podem ser justificados pelo perfil dos bovinos abatidos, pois ao verificarmos a relação de abate entre machos e fêmeas, vemos que os machos representaram mais de $94 \%$ dos animais abatidos, corroborando para interpretar que os bovinos na sua grande maioria eram de aptidão de corte.

Quanto ao percentual de condenações de carcaças por município, os dados demonstram uma grande distribuição espacial da tuberculose com municípios da região tocantina como Açailândia, Imperatriz, Senador La Rocque, municípios da região do médio mearim, como Bernardo do Mearim, região dos cocais, como Códó que se destacam na pecuária de corte e leiteira (IBGE, 2017), municípios da baixada maranhense, como Igarapé do Meio, região com baixa tecnologia em pecuária com compartilhamento 
de pastos entre produtores (Santos et al., 2016). Dentre os valores de prevalência se destaca o município de Pastos Bons com prevalência de 0,326\%, município com em torno de 520 propriedades e população bovina em torno de 19.000 bovinos, com mais de $90 \%$ das propriedades sem acesso a assistência técnica (IBGE, 2017), portanto isto demonstra que as prováveis causas da prevalência em destaque são movimentações de bovinos sem exames e falta de assistência técnica.

Pereira (2017), em estudo sobre a condenação de bovinos abatidos sob inspeção municipal em Santarém - PA no ano de 2016 encontrou em um total de 34.583 bovinos abatidos, sendo que foram abatidos 52.046 bovídeos ( 49.486 bovinos 2.560 bubalinos, com um total de 214 bovídeos condenados por tuberculose bovina ( 27 bovinos machos, 114 bovinos fêmeas, 20 bubalinos machos e 48 bubalinos fêmeas), demostrando pelo volume de bovídeos fêmeas abatidas que o perfil dos animais era diferente do atual estudo, corroborando para comprovar a importância do gado de aptidão leiteira para prevalência da tuberculose bovina em abatedouros frigoríficos.

Pereira (2011) citou condenações de bovinos e bubalinos por tuberculose bovina em abatedouros frigoríficos com Serviço de Inspeção Federal e Serviço de Inspeção Estadual no Pará, as condenações de vísceras ou miúdos, juntamente com a cabeça, dos abatidos no ano de 2017 no Estado do Pará, foram condenados 837.734 órgãos e 12.183 carcaças. Dos quais os pulmões apresentaram o maior número de condenações, correspondendo a $46,83 \%$; seguidas pelos rins com $17,1 \%$; cabeça $(10,1 \%)$; fígado $(9,7 \%)$; intestino $(4,6 \%)$, língua $(4,1 \%)$, coração $(4,0 \%)$, estômago $(2,2 \%)$ e carcaça $(1,4 \%)$.

Freitas (2019), em pesquisa de prevalência de tuberculose em condenações de bovinos em seis abatedouros frigoríficos, sendo que quatro abatedouros frigoríficos possuíam Serviço de Inspeção Estadual e dois sem Inspeção oficial, registou um total de 363 bovídeos (295 bovinos e 67 bubalinos) positivos de 158.290 bovídeos com prevalência de $0,23 \%$.

O estudo de casos registrados em mapas mensais de controle de exames de tuberculose por médicos veterinários autônomos habilitados no Programa Nacional de Controle e Erradicação de Brucelose e Tuberculose no Maranhão no período de 2013 a 2018 pesquisado por este estudo, demonstrou que no período analisado foram examinados 207.557 bovinos com registro de 20 casos positivos, representando uma prevalência de $0,009 \%$. A prevalência estimada pelo atual estudo foi inferior as registradas em estudos de inquéritos epidemiológicos em outras Unidades Federativas do Brasil, como Mato Grosso $(0,12 \%)$, Minas Gerais (5,04\%), Rio Grande do Sul (0,7\%), Paraíba (0,25\%), Bahia $(0,21 \%)$, Pernambuco (2,87\%) (Bahiense et al., 2016; Belchior et al., 2016; Figueiredo et al., 2010; Néspoli et al., 2016; Queiroz et al., 2016).

No Maranhão Pereira et al. (2009), realizou levantamento de prevalência de tuberculose bovina em bovinos leiteiros, demonstrando a importância da aptidão leiteira na cadeia epidemiológica com $12,12 \%$ de prevalência, valor superior a estudo com bovinos de mesma aptidão realizada por Silva Neto (2014), em propriedades leiteiras das regionais de São Luís, Bacabal e Pedreiras que encontrou uma prevalência 4,52\%.

Néspoli et al. (2016) em pesquisa de inquérito epidemiológico no estado de Mato Grosso em 2009 demonstrou uma prevalência de rebanhos de $1,3 \%$ e de animais positivos de $0,12 \%$. Ao estratificar o estado por regiões em acordo com a aptidão e finalidade de produção, quando comparadas as regiões por finalidade foi identificada a região com finalidade de cria com prevalência encontrada foi de 1,7\% para rebanhos e $0,24 \%$ para animais, seguida pela região de engorda com o mesmo em relação a aptidão a região com uma prevalência $0,7 \%$ para rebanho e $0,01 \%$ para animais, quando pesquisado por aptidão foi demonstrado que a região com aptidão leiteira apresentou $1.3 \%$ de prevalência para rebanhos e $0,04 \%$ para bovinos.

\section{Conclusão}

A tuberculose bovina no Maranhão é uma doença endêmica com grande importância para a saúde pública, sendo que fatores como sua ocorrência comprovada em várias regiões do estado, ausência de abatedouros frigoríficos e laticínios com inspeção oficial e em grande parte dos municípios do estado, sugestionam que os valores de prevalência estadual encontrados por este estudo podem estar subestimados, comprovando a importância da realização de um inquérito epidemiológico estadual para um real conhecimento da situação da doença no estado. 
O seu controle e erradicação no estado deve envolver uma interação melhor dos órgãos de defesa animal oficiais, inspeção, vigilâncias sanitárias, vigilâncias epidemiológicas e todos os elos da cadeia produtiva da carne para ter um conhecimento mais amplo dos casos em bovinos nas propriedades, abatedouros frigoríficos e casos em humanos em estabelecimentos de saúde municipais e estaduais para fundamentar ações de defesa animal mais eficazes.

Sendo necessário também reformulação de ações de Educação Sanitária permanente envolvendo criadores de bovinos, médicos veterinários autônomos habilitados no Programa Nacional de Controle e Erradicação de Brucelose e Tuberculose, funcionários (auxiliares de abate) de abatedouros frigoríficos, magarefes e profissionais de saúde pública para que haja mudança nos valores sociais, culturais, políticos e até financeiros de todos os envolvidos; consequentemente, gerando melhorias às condições sanitárias dos rebanhos.

\section{Referências bibliográficas}

AGED. Agência Estadual de Defesa Agropecuária do Maranhão. Disponível em <http://aged.ma.gov.br/febre-aftosa-pnefama>. Acessado em 23 out 2019.

ANUALPEC. (2019). Anuário da Pecuária Brasileira (20th ed., Vol. 1). Instituto FNP.

Bahiense, L., Ávila, L. N., Bavia, M. E., Amaku, M., Dias, R. A., Grisi-Filho, J. H. H., Ferreira, F., Telles, E. O., Gonçalves, V. S. P., \& Heinemann, M. B. (2016). Prevalence and risk factors for bovine tuberculosis in the State of Bahia, Brazil. Semina: Ciências Agrárias, 37(5), 3549-3559. DOI: 10.5433/1679-0359.2016v37n5Supl2p3549

Belchior, A. P. C., Lopes, L. B., Gonçalves, V. S. P., \& Leite, R. C. (2016). Prevalence and risk factors for bovine tuberculosis in Minas Gerais State, Brazil. Tropical Animal Health and Production, 48(2), 373-378. DOI: https://doi.org/10.1007/s11250-015-0961-x

BRASIL. Ministério da Agricultura, Pecuária e Abastecimento. DECRETO No 9.013, DE 29 DE MARÇO DE 2017. Regulamenta a Lei $n^{\circ} 1.283$, de 18 de dezembro de 1950, e a Lei $n^{\circ} 7.889$, de 23 de novembro de 1989, que dispõem sobre a inspeção industrial e sanitária de produtos de origem animal. Brasília: Casa Civil, Subchefia para Assuntos Jurídicos, 2017. Disponível em: <http://www.planalto.gov.br/ccivil_03/_ato2015-2018/2017/decreto/d9013.htm>

BRASIL. Ministério da Agricultura, Pecuária e Abastecimento. Inspeção de Carnes Bovinas Padronização de técnicas, Instalações e equipamento, 1971.

BRASIL. Ministério da Agricultura, Pecuária e Abastecimento. Regulamento da Inspeção Industrial e Sanitária de Produtos de Origem Animal. Decreto Lei $n^{\circ} 30.691$, de 29 de março de 1952, alterado pelos Decretos $n^{\circ} 1.255$, de 25 de junho de 1962, $n^{\circ} 1.236$, de 02 de setembro de 1994, $n^{\circ} 1.812$, de 18 de fevereiro de 1996, e $n^{o} 2.244$ de 04 de junho de 1997. Disponível em: $<$ http://extranet.agricultura.gov.br/sislegisconsulta/servlet/VisualizarAnexo?id=14013 > Acesso em: 12 mar. 2009.

Figueiredo, S. M., Rocha, V., Higino, S. S. S., Batista, C. S. A., Alves, C. J., Clementino, I. J., \& Azevedo, S. S. (2010). Tuberculose bovina no Estado da Paraíba: estudo retrospectivo. Pesquisa Veterinária Brasileira, 30(9), 712-716. DOI: https://doi.org/10.1590/S0100-736X2010000900002

Freitas, L. M. A. (2019). Pesquisa de Mycobacterium Bovis em lesões sugestivas de tuberculose em bovídeos abatidos nas regionais de Rosário, São Luís e Viana - Ma. São Luís, 2019. 67 fls. (Tese) - Mestrado profissional em defesa sanitária animal. UEMA. São Luís.

IBGE. Indicadores IBGE. Estatística da produção pecuária. Disponível em: $<$ https://www.ibge.gov.br/estatisticas/economicas/agricultura-e-pecuaria/21814-2017-censoagropecuario.html?=\&t=downloads $>$ Acesso em: 22 out 2019.

Ministério da Agricultura, Pecuária e Abastecimento 〈http://www.agricultura.gov.br/assuntos/inspecao/produtos-animal/sif/servico-de-inspecao-federal-sif $>$.

Néspoli, J. M. B., Negreiros, R. L., Amaku, M., Dias, R. A., Ferreira, F., Telles, E. O., Heinemann, M. B., Grisi-Filho, J. H. H., Gonçalves, V. S. P., \& Neto, J. S. F. (2016). Epidemiological situation of bovine tuberculosis in the state of Mato Grosso, Brazil. Semina: Ciências Agrárias, 37(5), 35893599. DOI: 10.5433/1679-0359.2016v37n5Supl2p3589 
Pereira, A. M. (2011). Causas de condenação de carcaças e órgãos de bovinos em frigoríficos sob serviço de inspeção federal no estado do Maranhão: tendência histórica e perdas econômicas. Universidade Federal Rural do Rio de Janeiro.

Pinto, P. S. A. (2008). Inspeção e higiene de carnes. In Viçosa: Editora UFV. Universidade Federal de Viçosa.

Queiroz, M. R., Groff, A. C. M., Silva, N. S., Grisi-Filho, J. H. H., Amaku, M., Dias, R. A., Telles, E. O., Heinemann, M. B., Neto, J. S. F., \& Gonçalves, V. S. P. (2016). Epidemiological status of bovine tuberculosis in the state of Rio Grande do Sul, Brazil. Semina: Ciências Agrárias, 37(5S Supl. 2), 3647-3658.

Roug, A., Perez, A., Mazet, J. A. K., Clifford, D. L., VanWormer, E., Paul, G., Kazwala, R. R., \& Smith, W. A. (2014). Comparison of intervention methods for reducing human exposure to Mycobacterium bovis through milk in pastoralist households of Tanzania. Preventive Veterinary Medicine, 115(34), 157-165. DOI: https://doi.org/10.1016/j.prevetmed.2014.04.014

Sabedot, M. A., Boetcher, A. V., Pozza, M. S. S., Busanello, M., \& Mangoni, J. (2009). Ocorrência de tuberculose e brucelose em rebanhos da região sudoeste do Paraná. Revista Científica Eletrônica de Medicina e Veterinária, 7(12).

Santos, C. L. R., Santos Júnior, J. B., Cunha, M. C., Nunes, S. R. F., Bezerra, D. C., Torres Júnior, J. R. S., \& Chaves, N. P. (2016). Nível tecnológico e organizacional da cadeia produtiva da bubalinocultura de corte no estado do Maranhão. Arquivos Do Instituto Biológico, 83. DOI: https://doi.org/10.1590/1808-1657000022014

Silva Neto, J. P. (2014). Frequência de anticorpos contra Mycobacterium bovis em rebanhos leiteiros nas regionais de São Luís, Bacabal e Pedreiras - Maranhão .2014.69 fls. Dissertação (Mestrado em Mestrado Profissional em Defesa Sanitária Animal) - Universidade Estadual do Maranhão. São Luís.

Recebido: 5 de abril, 2020.

Aprovado: 21 de maio, 2020.

Disponível online: 20 julho, 2020 .

Licenciamento: Este artigo é publicado na modalidade Acesso Aberto sob a licença Creative Commons Atribuição 4.0 (CC-BY 4.0), a qual permite uso irrestrito, distribuição, reprodução em qualquer meio, desde que o autor e a fonte sejam devidamente creditados 